\title{
PROJETOS EDUCACIONAIS PARA UM BRASIL-NAÇÃO: UMA REFLEXÃO SOBRE A EDUCAÇÃO BRASILEIRA NO PROCESSO DE TRANSIÇÃO IMPÉRIO-PRIMEIRA REPÚBLICA (1850-1930)
}

\author{
Ruben Maciel Franklin ${ }^{1}$ \\ lattes.cnpq.br/7015182150922669
}

Resumo: O presente artigo tem como objetivo delinear, em linhas gerais, a trajetória de organização escolar brasileira entre a segunda metade do século XIX e as primeiras décadas do século XX. Retomamos as diversas ações empreendidas pelo Governo Imperial no intuito de combater a precariedade do sistema educacional, bem como as alternativas levantadas na Primeira República no sentido de atacar o elevado índice de analfabetismo do "grosso" da população. Procuramos, entre os anos 1850 e 1920, discutir as "inovações" que foram sendo introduzidas na educação brasileira, assim como os debates sobre os tipos de disciplinas (castigos físicos e imposições morais) a serem testadas nas escolas. Problematizamos, igualmente, a relação existente entre os novos métodos de alfabetização e o surgimento de um sentimento de nacionalidade.

Palavras-chave: Educação; Brasil; Império; Primeira República; Alfabetização.

\section{EDUCATIONAL PROJECTS FOR A BRAZIL-NATION: A REFLECTION ON THE BRAZILIAN EDUCATION IN THE TRANSITION PROCESS OF EMPIRE-FIRST REPUBLIC (1850-1930)}

\begin{abstract}
This article aims to approach, in general, the trajectory of Brazilian educational organization between the second half of the nineteenth century and the first decades of the twentieth century. We resumed the various actions taken by the Imperial Government in order to combat the precariousness of the educational system as well as the alternatives raised in the First Republic to attack the high illiteracy rate of "bulk" of the population. We seek, between the years 1850 and 1920, to discuss the "innovations" that have been introduced in Brazilian education, as well as dialogues on the type of discipline (corporal punishment and moral impositions) to be tested in schools, arguing also on the ratio of literacy methods and the emergence of a sense of nationhood.
\end{abstract}

Keywords: Education, Brazil, Imperial Government, First Republic, Literacy.

\footnotetext{
${ }^{1}$ Doutor em História Social. Docente na Universidade da Integração Internacional da Lusofonia Afro-Brasileira (Brasil). Contato: rbnhist@yahoo.com.br.
} 


\section{Contextualizando, o Brasil no caminho da urbanização e das reformas educacionais}

Ao entrar na segunda metade do século XIX, o cenário político, social e econômico brasileiro se mostrava bastante conturbado. O país acabara de sair de um turbulento período regencial, o qual deflagrara lutas separatistas em diversas regiões (as revoltas regenciais). As províncias se encontravam, interiormente, vulneráveis: a produção da lavoura tradicional (algodão e o açúcar) estava entrando em declínio, ao passo que as disposições partidárias acirravam os ânimos dos latifundiários no que se refere aos debates sobre as formas de propriedade agrícola, o alcance das reformas políticas e a situação da mão de obra escrava. A "nação" brasileira em formação, como resumiu o historiador Capistrano de Abreu, surgia como o resquício do contato entre diversas raças, sobrevivendo em diferentes condições geográficas e se ocupando da luta pela posse da terra e do ódio aos portugueses e a si mesmas: o resultado de 300 anos de colonização. (ABREU, 1988).

A solução emergencial para esta crise apareceu com o advento da lavoura cafeeira, que, a partir de 1840, já começara a propiciar lucros. Todavia, apesar da economia se manter em base agrícola, recuperando-se das perdas da cana-de-açúcar, as relações socioeconômicas que o cultivo do café introduziu na sociedade brasileira foram de ordem bastante distintas. Como afirmou Nelson W. Sodré (1973, p. 226):

Nem a lavoura do café, atividade econômica preponderante, era semelhante a do açúcar (...), nem a sociedade que seria por ela gerada era semelhante à sociedade açucareira. (...) O que a distingue, entretanto, é a capacidade para, aproveitando o que existia de velho no Brasil, gerar o novo. (...). Será, assim, fundada na grande propriedade e no trabalho escravo (...) vinculada ao mercado externo (...). Mas à medida que se libera e se desenvolve (...) desembaraça-se pouco a pouco do elemento escravo (...) alicerça o surto demográfico e leva a urbanização ao interior.

O que aconteceu, nesse processo, foi a passagem de uma economia exportadora de alicerce rural-agrícola para uma na qual os interesses ur- 
banos e comerciais foram adquirindo cada vez mais força, contrabalançando as relações de forças entre mundo urbano e rural. As cidades passaram a ser polos geradores de atividades que criavam todo um atrativo populacional, culminando num largo movimento de migração. Assistiuse, igualmente, o desenvolvimento de uma camada social média (religiosos, militares e comerciantes) à medida que as classes trabalhadoras, compostas por artesãos especializados, caixeiros, comerciantes, sapateiros, costureiros, ambulantes, operários de empresas estrangeiras, passaram a compor parte considerável da população. Nesse contexto, algumas mudanças no sistema educativo se tornaram imperativas no sentido de atender a formação e a habilitação técnica adequada para o exercício de novas funções burocráticas ou empregos urbanos de menor porte. $\mathrm{Mu}-$ danças estas que, não obstante, ficaram inicialmente restritas ao ambiente da Corte, situada no Rio de Janeiro.

Podemos elencar algumas dessas realizações, como a criação de Inspetoria Geral da Instrução Primária e Secundária (1854), a qual tinha o objetivo de fiscalizar e orientar o ensino público e particular, a criação de normas voltadas à liberdade de ensino e a preparação de professor primário, a reformulação dos colégios preparatórios, entre outras. No entanto, o interesse econômico-político-social dos grupos dominantes (políticos, comerciantes e fazendeiros) restringiu-se, sobretudo, ao ensino superior. As modificações propostas em outros níveis de ensino foram puramente superficiais, isto porque estes grupos sociais mais privilegiados não desejavam alterar a estrutura social geral e/ou educacional, tendo em vista a necessidade de conservar o status e os privilégios reservados a algumas funções específicas no âmbito do bacharelado. Sendo assim, a precariedade do ensino primário se tornou uma constante, visto que as políticas governamentais se preocuparam apenas em suportar o nível superior como uma garantia de formação da elite dominante. O intuito era manter os cursos preparatórios e os exames parcelados para o ingresso no curso superior. Consequentemente, segundo o relatório do dr. Justiniano José da Rocha (1850), “os pais não ansiavam pela aprendizagem de seus filhos, mas apenas que estes fossem o mais rápido possível preparados aos exames preparatórios”. O próprio Colégio Pedro II (1838), criado 
para ser o exemplo em alto padrão de ensino, fora reduzido a um curso preparatório, por meio da Reforma José Bento da Cunha Figueiredo (1876-1878).

\section{Da coerção física a imposição moral, ou uma leitura do Conto de Escola}

Dito isso, podemos caminhar na direção do que era entendido como escola e instrução formalizada, esboçando um panorama de como as práticas disciplinares que marcaram o sistema de ensino durante o Império, as quais caracterizadas pela rigidez e violência dos "mestres", foram pouco a pouco sendo "substituídas" pelos métodos mais "eficazes" pautados na moral e na civilidade. Para isso, utilizaremos o Conto de Escola, de Machado de Assis (1839-1908), um texto publicado em 1884, que faz referências ao uso da violência na educação escolar em meados do século XIX. O conto, narrado em primeira pessoa, é iniciado com a especificação de data e de local:

A escola era na Rua da Costa, um sobradinho de grade de pau. O ano era de 1840. Naquele dia - uma segunda-feira, do mês de maio - deixei-me estar alguns instantes na Rua da Princesa e ver onde iria brincar a manhã (...) (ASSIS, online)

O personagem Pilar (narra sua história quando criança), tendo em vista as opções de locais de brincadeiras, prefere mesmo se dirigir para a escola. Motivo: uma surra que levara do pai (uma sova de vara de marmeleiro), por ter faltado duas vezes às aulas. No colégio, recebe de outro menino, Raimundo, filho do mestre, uma proposta: ganhar uma moeda de prata em troca de uma explicação. Todavia, outro aluno, Curvelo, escuta a transação e delata seus eventuais colegas. O impetuoso professor, chamado Policarpo, decide então castigar os meninos, açoitando-os com uma palmatória. Após a promessa de vingança por parte de Pilar, Curvelo "foge com medo". Pilar, tendo sonhado com a referida moeda, sai à procura desta no dia seguinte, sabendo que o professor a havia atirado à rua antes de puni-lo. Já adulto, o narrador sentencia que Raimundo e Curve- 
lo foram os primeiros a lhe mostrar a existência, respectivamente, da corrupção e da delação.

O conto traz, dessa maneira, os tortuosos caminhos da formação moral, a qual não se fazia a parte de excessiva severidade e rigor paternal. O professor poderia usar e usava de sua máxima autoridade, aplicando castigos corporais, de modo que aliava a repressão social ao processo educativo, promovendo a disciplina escolar por meio de ameaças verbais e violência física. Dessa forma, ao rememorar o professor, o narrador diz que "O pior que ele podia ter, para nós, era a palmatória. E essa lá estava, pendurada do portal da janela, à direita, com seus cinco olhos de diabo. Era só levantar a mão, dependurá-la e brandi-la, com a força de costume que não era pouca (ASSIS, online).

Não obstante, passa a descrever a prática punitiva:

(...) estendi-lhe a mão direita, depois a esquerda, e fui recebendo os bolos uns por cima dos outros, até completar doze, que me deixaram as palmas vermelhas e inchadas. (...). Acabou, pregounos outro sermão. Chamou-nos sem-vergonhas, desaforados, e jurou que se repetíssemos o negócio, apanharíamos tal castigo que nos havia de lembrar para todo o sempre. E exclamava: porcalhões! Tratantes! Faltos de brio! (ASSIS, online).

O emprego da violência punitiva no trato educacional não foi um método esporádico ou acidental no período em questão, antes se configurou como um elemento típico de uma formação escolar autoritária e centrada na figura do "Mestre-pai", que deixou marcas profundas na estrutura do ensino brasileiro (RIBEIRO, 2003). Estas práticas, que tinham como finalidade garantir a passividade do "Aprendiz-filho", isto é, a postura respeitosa e o comportamento aceitável - não só a palmatória, mas beliscões, "reguadas", puxões de orelha ou obrigação de se ajoelhar em caroços de milhos -, por sua vez, só vieram a ser questionadas na segunda metade do século XIX, quando surgiram os mecanismos ditos mais "civilizados" de imposição disciplinar: os castigos morais.

Uma transição que, contudo, ocorreu embaixo de intensos debates que envolviam professores, educadores, funcionários do Estado, os pais de alunos e, especialmente, os médicos higienistas. Foram estes últimos 
que desenvolveram uma série de propostas, pelas quais a ação médica regularia os costumes e a vida social em geral, por isso, a escola ter sido um dos seus alvos principais. Para estes, o saber médico deveria formar uma "pedagogia científica", que fiscalizasse as condições ambientais da escola e que produzisse "pessoas higiênicas, higienizados e higienizadores".

Tal visão pedagógica propunha a alteração dos currículos, métodos de ensino e manuais didáticos, de modo a instituir uma relação "civilizada” entre mestres, funcionários e alunos. De tal modo, tornava-se primordial a abolição dos castigos corporais.

O regulamento de 1854 promoveu diversas mudanças nas regras anteriores, estabelecia, no lugar dos castigos físicos, punições que iam da repreensão e realização de tarefas fora do horário escolar à comunicação aos pais para castigos maiores e expulsão da escola. (LEMOS, 2005, p. 80).

Mesmo diante de tal expectativa de lei, alguns pais ainda burlavam as prerrogativas e chegavam a autorizar, por escrito, os castigos físicos, enquanto os professores alegavam agir com "sentimentos de piedade paternal", ou seja, de possuírem uma autoridade paterna ao aplicarem os castigos. Havia uma falta de consenso entre educadores, higienistas e pais; muitos dos professores se resguardavam o direito de utilizar a violência, entrando em confronto com os delegados de instrução. Os próprios higienistas às vezes se colocavam contra ou a favor dos métodos severos de disciplina.

Apesar da difusão do novo método moral, as denúncias sobre práticas de castigos corpóreos eram constantes. Ao recebê-las a Inspetoria geral de Instrução Pública investigava, caso comprovadas, os responsáveis eram punidos. Para essa nova orientação, os professores deveriam encarar a carreira do magistério como um "sacerdócio" de provação diária. No entanto, o que se verificou foi que entre a lei e a prática o caminho era extenso e tortuoso e muitos abusos permaneceriam ocorrendo no cotidiano escolar, como que validando uma prática "tradicional". 


\section{No Império, a educação \\ como o símbolo da Nação}

Os anos que sucederam 1850 foram marcados por aceleradas mudanças socioeconômicas. O fim do tráfico de escravos e o cultivo do café disponibilizaram capitais e rendas. O Brasil passou a ter maior contato com as nações europeias, de onde importava não só maquinarias e ferramentas, mas também novas ideias, as quais passaram a circular no pequeno meio intelectual brasileiro. Ideias estas que, embasadas tanto no liberalismo quanto no cientificismo, vincularam-se às práticas educacionais por meio de projetos para a reformação da cultura educacional nativa. Logo, as reformas aqui empreendidas se enraizaram em modelos importados, não condizendo com a realidade social brasileira.

Em 19 de abril de 1879, foi decretada a Lei Leôncio de Carvalho, a qual estabeleceu algumas medidas no sentido de impulsionar a educação: liberdade de ensino, exercício do magistério, liberdade de frequência, isto é, liberdade para os alunos dos níveis secundários e superiores estudarem da forma que escolhessem. Porém, poucas foram as consequências práticas. O século XIX também testemunhou ensaios do governo imperial em interligar a educação com a fabricação da ideia de nacionalidade, utilizando-se de projetos relacionados à formação da cidadania e do Estado brasileiro.

Com a implantação do ensino secundário no Brasil (2. ${ }^{\circ}$ reinado/ 1840-1889), muitos educadores, sobretudo, na Corte, tentaram reformular o ensino pela criação de métodos inovadores de alfabetização. Para isso, utilizaram "boas dosagens" de imaginação. Este foi o caso do curioso método Bacadafá: idealizado no início da década de 1870 por Pinheiro de Aguiar, professor de escola primária no Rio de Janeiro. O Bacadafá visava alfabetizar jovens e adultos, além de disseminar noções de geografia e história pátrias a fim de engendrar o sentimento de nacionalidade.

As principais virtudes do método, de acordo com seu criador, “(...) eram a rapidez com que prometia alfabetizar as crianças (20 dias!) e os adultos, como também a capacidade de levar os alunos a se identificarem com símbolos e imagens da pátria”. (SCHUELER, 2004, p. 81). No geral, 
o método realizava a convergência de imagens, como a do índio ("a raiz da nacionalidade"), a textos que exaltavam o amor e o respeito ao povo e à nação. As lições consistiam na construção, pelos alunos, de vários con-

Figura 1 - O método Bacadafá. Fonte: SCHUELER, Alessandra Frota. Aprendendo a ler com a história.

\section{METHODO BACADAFA'}

Para base findamental do methodo estabeleceu quatro nomes indistinctos, que os classificou como nomes de personagens indigenas, formando uma familia pelo modo seguinte:

O Indio pai A India mãi A india filha O Indio fllho
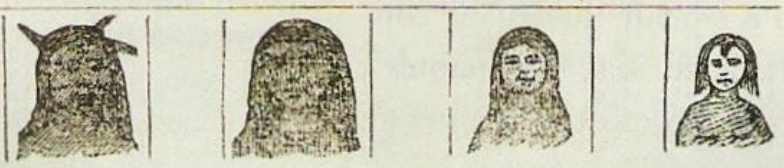

B ba

G ga

$\mathrm{N}$ na

C ca

J ja

P pa

I'ta

D da

L la

$\mathrm{R}$ ra

V va

F fa

IM ma sa

$\mathrm{X} \times \mathrm{za}$

$\mathrm{Z} \mathrm{za}$

() aprendiz, fallando os quatro nomes verticaes dos indios, fica conhecendo as 16 letras consoantes do alphabeto, fórma syllabas com a rogal a sem ser preciso dizer nomes de letras; basta só conhecer á qual das personagens pertencem. juntos silábicos, os quais detinham uma base inicial. Essa base era composta pelas sílabas iniciais retiradas dos nomes (acompanhados das respectivas imagens) de índios guaranis: Bacadafá, Galajara, Naparasa e Tavaxaza. (Figura 1). Os quadros eram reproduzidos à mão no quadronegro ou em cartões impressos, depois distribuídos aos alunos juntamente com uma cartilha.

Dessa maneira, associando "soletração", "silabação" e "palavração", os alunos formavam

palavras e frases, as quais eram resultantes do conjunto de sílabas construído com base nos nomes indígenas. O método Bacadafá foi, assim, vangloriado na segunda metade do século XIX, não só por suas virtudes educativas, mas também por ter sido criado no país, isto é, ser um produto originalmente nacional.

Nas palavras de Antônio Estevam Costa, o método era: 
Um vastíssimo campo para um professor instruído! Sobre aqueles índios, íncolas brasileiros, seus costumes, seu caráter, suas guerras com os conquistadores, e, de dedução em dedução, sobre a rica madeira a natureza do país (...) o café, o algodão, o açúcar, as minas e os minerais (...) a sanguinária história da América espanhola e Portuguesa (...) e, depois, a divisão histórica e política do Império, a comunhão brasileira das províncias e de cuja união resulta o poder e a força da nação, a força representativa, os deveres do cidadão, a Constituição do Estado (COSTA Apud SCHUELER, 2004, p. 82).

Tido por criativo, nacional e engenhoso, o método Bacadafá representava uma mentalidade evolucionista, um presente glorioso, o império civilizado, uma educação que visava construir, simbolicamente, a nação.

O final do século XIX também foi marcado pelo aparecimento do ensino feminino em nível secundário, um resultado da iniciativa particular. Nesse sentido, cabe destacar a atuação dos protestantes norteamericanos em alternativas inovadoras na educação brasileira. Estes trouxeram uma experiência até então desconhecida no âmbito educacional brasileiro quando da abertura, em 1881, do primeiro colégio Metodista do país, o qual priorizou a educação feminina num período em que as mulheres eram reclusas à vida doméstica e instruídas, especialmente, para o matrimônio.

A entrada dos Metodistas no ensino privado brasileiro se deu pela iniciativa da educadora Martha Watts (1845-1920), ao fundar, em 1881, o colégio Piracicabano, numa área próxima à primeira Igreja Metodista fundada no país4. Tempo em que as elites, no que concerne à educação, utilizavam preceptores. Já com relação ao grosso da população, poucos conseguiam alcançar vagas nas escolas elementares. No que se refere à instrução secundária, a marginalização era ainda mais insofismável, destinando-se, sobretudo, às classes abastadas. Nesse período, de acordo com Beatriz V. Elias:

\footnotetext{
4 Fundado por John Wesley, na Inglaterra, no séc. XVII, o movimento metodista se transformara, depois da Guerra Civil Americana (1861-1865), na mais poderosa denominação religiosa dos EUA, em função do número de adeptos, do poder econômico e de sua obra educativa.
} 
As escolas públicas do Brasil eram extremamente precárias, funcionavam em prédios adaptados e, muitas vezes, na residência do professor. As classes - com alunos de diferentes idades e graus de conhecimento e em número excessivo - eram atendidas por apenas um professor, em geral não habilitados a ministrar aulas. $\mathrm{O}$ currículo adotado não ia além das primeiras letras, noções de gramática portuguesa, um pouco de aritmética, além de aulas avulsas de francês e latim. (ELIAS, 2005, p. 82).

Doravante tal realidade, as mudanças trazidas pelos metodistas causaram grande impacto na educação do país. As inovações já começavam pelos prédios: a arquitetura se distinguia pelas salas amplas, construídas especificamente para a atividade de ensino. As salas de aula também eram mistas e as carteiras individuais. Havia salas especiais (Música, Geografia) e o Kindergarten, que foi uma antecipação aos futuros jardins-de-infância. Também foram implantados laboratórios com várias horas de ensino diário, além da adoção de um sistema de ensino a ser avaliado pela comunidade.

Os recursos investidos na criação das escolas metodistas eram provenientes da WMS (Woman's Missionary Society), ou seja, de membros das igrejas metodistas americanas. A partir da ação dessas igrejas, várias iniciativas foram viabilizadas, e os colégios metodistas se multiplicaram, sendo criados também no Rio de Janeiro, Petrópolis, Ribeirão Preto e Belo Horizonte. Apesar de sua aberta intenção religiosa, as propostas inovadoras dos metodistas ganharam boa recepção e se transformaram no "embrião" da futura reforma educacional realizada por Prudente de Moraes na instrução pública.

As duas últimas décadas do Império foram marcadas por diversas "questões": libertação dos escravos, reforma eleitoral, positivismo militar, instituição republicana e religiosa. Esta última devido ao confronto da Igreja Católica com a Maçonaria, uma instituição filantrópica e humanitária, a qual se dizia detentora do ideal das "Luzes", racionalista e que funcionava de forma a combater o fanatismo e a obscuridade, expressados, segundo ela, na religião.

Num final de século, em que o movimento católico se expressou no ultramontanismo, o qual visava o restabelecimento do ensino religioso 
nas escolas, cabe-nos ressaltar a ação da Maçonaria no âmbito educacional. Não mais perseguidos, como na primeira metade do século XIX, os maçons - ou "herdeiros das Luzes" -, espalharam-se por diversas regiões, por meio das Lojas Maçônicas, procurando afirmar a Maçonaria como uma escola onde prevalecia a liberdade de pensamento e o racionalismo. Apesar dos constantes atritos com a Igreja Católica, as Lojas Maçônicas passaram por um processo gradativo de expansão, passando de pouco mais de duzentas lojas, em 1885, para mais de seiscentas no início do século XX. Um aumento que também foi acompanhado pela ampliação de suas atuações, atingindo os campos da beneficência, do auxílio mútuo e da educação.

Foi justamente este último campo o mais utilizado pela Maçonaria para a divulgação de seus ideais. Foram realizados altos investimentos na construção de uma rede escolar, na criação de "aulas noturnas", bem como na abertura de bibliotecas. Dessa forma, a Maçonaria deveria "atuar sobre a educação que dá a primeira forma aos corações humanos, sobre as sociedades que agrupam indivíduos e, assim, influindo sobre os governos que caminham à frente das sociedades" (Aurora Escocesa, 1881 Apud BARATA, 2005, 23). O engajamento da Maçonaria na esfera educacional, começando por volta de 1870, atingiu seu apogeu no limiar do século XX. Ao "pregarem" o ensino laico no sentido de combaterem aos que eles chamavam de inimigos do "progresso" - partidários da ignorância, do fanatismo e da intolerância -, os maçons colocaram em cena questões circunstanciais que, em breve, levariam o Império à ruína.

\section{A República e a educação como patriotismo e civilidade}

A 15 de novembro de 1889, o povo assistiu "bestializado" a proclamação da República. Para o historiador José Murilo de Carvalho (1987), o movimento mais pareceu uma parada militar, sem luta, sem desavenças, sem a participação popular. Uma República que tentaria se legitimar por meio de "tradições inventadas" (HOBSBAWM; RANGER, 1984), ou 
seja, pela manipulação simbólica de imagens que pudessem conduzir o povo na direção do sentimento de nacionalidade. Procurou-se, assim, construir a representação ideal de um herói republicano, ligado aos valores do cristianismo, como foi o caso de Tiradentes, ou perpetuar a adoção de novos costumes citadinos pela importação de comportamentos e valores - sobretudo, da França - voltados para uma sociedade mais urbanocomercial e burguesa, a "invenção" da Belle-Époque.

Politicamente, o que prevaleceu foi a política do café-com-leite, representando, respectivamente, os estados de São Paulo e de Minas Gerais, os quais dominaram o cenário político brasileiro durante a República Velha (1894-1930), elegendo ora um ora outro o Presidente da República (LESSA, 1988). A eleição era garantida pela Política dos Governadores, acordo entre os políticos que organizavam internamente o sistema a partir do fazendeiro-coronel, possuidor do seu "curral" eleitoral, passando por prefeitos e governadores, até chegar ao Presidente.

A sociedade brasileira consolidava sua guinada urbana, com a classe média em franco crescimento, a qual se apoderava de todas as maneiras dos cargos públicos, beneficiando-se de uma burocracia corrupta, o que levou o historiador Nicolau Sevcenko (1983) a falar de uma "república de arrivistas". Nesse contexto, o analfabetismo, legado da política educacional do Império que se importou, maiormente, com as classes abastadas, passou a constituir um sério problema, visto que as práticas de leitura e escrita foram se tornando cada vez mais necessárias à integração no novo contexto social.

Contudo, as reformas educacionais republicanas, como o Código Epitácio Pessoa (1901), que acentuava o ensino literário, e a reforma Rivadávia (1911), de orientação positivista (liberdade de ensino), não conseguiram seu objetivo de valorizar o ensino elementar e secundário recaindo sobre uma formação integral do aluno, ao invés de apenas treinálo para os exames preparatórios dos cursos superiores. Nesse sentido, a reforma Carlos Maximiliano (1915) também não obteve êxito. A república dos arrivistas ditava a ideologia da classe média e as elites estavam interessadas em fazer dos filhos os burocratas por excelência, os digníssimos 
doutores. A maioria da população residente no campo, no entanto, continuava marginalizada da educação.

Essa situação é bem representada no romance São Bernardo, de Graciliano Ramos, quando o personagem-narrador Paulo Honório, dono de uma fazenda no sertão nordestino, é especulado sobre a possibilidade de construir uma escola para os filhos dos seus trabalhadores no interior da fazenda. Concordando com a proposta, ele constrói um quartinho, contrata um professor e compra o material, sempre indignado por estar gastando uma quantia de seis mil-réis com “moleques", que, segundo ele, não teriam outro futuro, senão o trabalho manual de seus pais. Sendo assim, para que aprenderiam a ler e escrever?! Contudo, a própria constru-

Figuras 2 e 3 - Capa de O tico-tico e página comemorativa. Fonte: AZEVEDO, Ezequiel de. O Tico-Tico. Cem anos de Revista. São Paulo: Via Lettera, 2005.
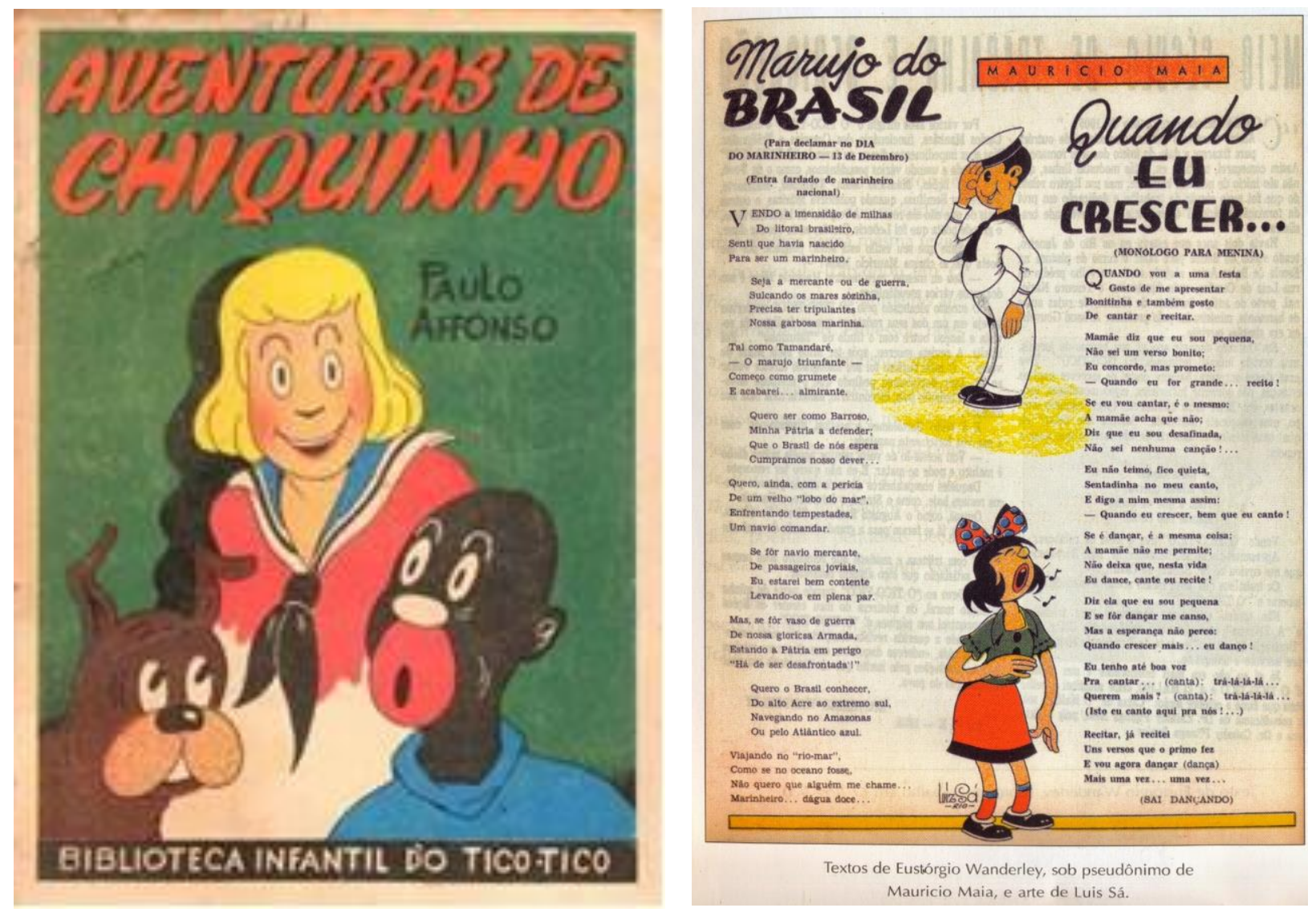

ção da escola era intimamente ligada às suas alianças políticas. Honório estava cumprindo uma ordem do Governador, que tinha como objetivo demonstrar que no seu governo o índice de analfabetismo havia diminuí- 
do, e o número de crianças na escola havia aumentado. Era a hipocrisia da República Velha.

Voltando ao objetivo republicano de formar cidadãos dotados de valores cívicos e patrióticos, torna-se importante enfatizar as influências socioculturais exercidas pela revista infantil $O$ tico-tico, a qual, publicada a partir dos anos 1920, tinha por princípio "inventar" uma identidade nacional por intermédio da prática educativa.

Não me atentarei aqui em explicar o processo de criação dessa revista, mas antes ao seu cunho educacional quando tinha por objetivo traduzir a cidadania brasileira por meio de valores oriundos de uma classe média em ascensão. $O$ tico-tico acompanhava as transformações históricas dessa transição Império-República, preocupando-se, sobretudo, com a formação moral das crianças, no sentido de formar, ao longo dos anos, homens íntegros e tementes a Deus. Portanto, uma revista direcionada para o público infantil, mas cujo conteúdo tinha que passar pela aprovação de pais e professores, isto é, os conservadores dos "bons costumes". Nesse guia, os criadores da revista mantiveram o cuidado de privilegiar a rotina educativa e moral da publicação, preservando-a sempre à luz do “espírito" didático/moralista então dominante. A revista $O$ tico-tico representou as intenções republicanas de se moldar a moral a partir de valores dos grupos sociais dominantes, uma manifestação do "espírito" positivista, que marcou a República Velha.

As proposições moralistas e educativas que mesclavam elementos cívicos, patrióticos e religiosos (catolicismo) apareciam em várias seções da revista, destacando-se nos contos infantis, nas poesias ufanistas, nas lições sobre o respeito aos mais velhos, na solidariedade racial e nos benefícios da dedicação às boas obras. O princípio educativo aparecia ainda nas biografias que celebravam os feitos dos personagens ilustres (generais e presidentes) da história brasileira, os quais, como numa história magistrae vitae, eram exemplos a serem seguidos por meninos e meninas. Basta olharmos uma de suas capas para termos ideia de como o conteúdo educativo se emaranhou com a "invenção" de uma identidade brasileira customizada nas trocas (e modelos) raciais e no aprendizado mú- 
tuo, das diferenças sociais e dos espaços e comportamentos adequados aos diferentes grupos que constituíam a nascente República.

A revista funcionava, nas palavras de Carlos Drummond de Andrade, como "uma escola disfarçada de brincadeira", misturando-se, assim, perfeitamente, ao projeto republicano de construir uma Nação.

\section{Considerações finais}

A educação brasileira, no período estudado (1850-1920), foi caracterizada por inúmeras transformações que os educadores impuseram aos métodos de ensino, sem, contudo, ampliá-lo de uma forma que viesse atender a maioria da população. Tanto no Império quanto no início da República, os grupos dominantes sempre tiveram acesso privilegiado à educação. À medida que as "séries" se elevavam: primária, secundária e superior, menor era a participação dos setores mais empobrecidos. Métodos curiosos e inovadores de alfabetização também não vingaram. As inovações americanas, por sua vez, ficaram mais restritas à parte Sul do país. Já a Maçonaria tivera sua aceitação contida pela suspeita da população, em sua maioria católica, e a educação moral e cívica da Primeira República contrastava com a ineficiência do novo regime em impor reformas que condissessem com a realidade social local. Dessa forma, a formação educacional de viés nacionalista se encaminhou por várias ramificações, as quais de maneira alguma convergiram no intuito de democratizar o ensino e/ou transformar o abismo das desigualdades socioeconômicas do país. Uma preocupação com o sistema educacional que, ao invés de processar mudanças progressistas, se viu presa a uma rede de privilégios e favorecimentos.

\section{Referências}

ABREU, João Capistrano de. Capítulos de História Colonial. Belo Horizonte: Itatiaia, 1988. 
ASSIS, Machado de. Conto de Escola. Disponível em: $<$ http://www.biblio.com.br/>.

AZEVEDO, Ezequiel de. O Tico-Tico. Cem anos de Revista. São Paulo: Via Lettera, 2005.

BARATA, Alexandre Mansur. Compasso e esquadro na sala de aula. Nossa História, n. 2, jun. 2005, ano 2.

. Luzes e sombras: a ação da Maçonaria brasileira (1870-1910).

Campinas: CMU- Editora da Unicamp, 1999.

CARVALHO, José Murilo de. Os bestializados: o Rio de Janeiro e a República que não foi. São Paulo: Companhia das Letras, 1987.

ELIAS, Beatriz Vicentini. Inovação Americana na educação do Brasil. Nossa História, n. 23, set. 2005, ano 2.

HOBSBAWM, Eric; RANGER, Terence. A invenção das tradições. Rio de Janeiro: Paz e Terra, 1984.

LEMOS, Daniel Albuquerque. Entre a palmatória e a moral. Nossa História, n. 15, jan. 2005, ano 2.

LESSA, Renato. A invenção republicana. São Paulo: Vértice, 1988.

RAMOS, Graciliano. São Bernardo. Rio de Janeiro/São Paulo: Record, 1995.

RIBEIRO, Maria Luiza Santos. História da Educação Brasileira: a organização escolar. Campinas, SP: Autores Associados, 2003.

ROSA, Zita de Paula. O tico-tico: meio século de ação recreativa e pedagógica. Bragança Paulista: Editora Universitária São Francisco, 2002.

SCHUELER, Alessandra Frota. Aprendendo a ler com a história. Nossa História, n. 14, dez. 2004, ano 2.

SEVCENKO, Nicolau. Literatura como missão: tensões sociais e criação cultural na Primeira República. 1. ed. São Paulo: Brasiliense, 1983.

SODRÉ, Nelson Werneck. Formação histórica do Brasil. 8. ed. São Paulo: Brasiliense, 1973.

XAVIER, Maria Elizabete S. Prado. Poder político e educação de elite. 3. ed. São Paulo: Cortez, Autores Associados, 1992.

Recebido em 17 de dezembro de 2015. Aprovado em 17 de abril de 2016. 